\title{
Hydroalcoholic Extract of Eugenia uniflora as Denture Disinfectant: Antimicrobial Activity and Effect on the Physical Properties of Polymethylmethacrylate
}

\section{Débora Oro Ferrari ${ }^{1}$}

https://orcid.org/0000-0002-7360-3801

\section{Luana Zanella ${ }^{2}$}

https://orcid.org/0000-0001-6828-7229

Rafael Guerra Lund ${ }^{3}$

https://orcid.org/0000-0003-1006-3809

\section{Walter Antônio Roman Júnior 4}

https://orcid.org/0000-0001-8363-8795

\section{Sinval Adalberto Rodrigues-Junior ${ }^{4 *}$}

https://orcid.org/0000-0002-4475-1725

${ }^{1}$ Prefeitura Municipal de São Miguel do Oeste, Secretaria Municipal de Saúde, São Miguel do Oeste, Santa Catarina, Brazil; 'Universidade Federal da Fronteira Sul, Programa de Pós-Graduação em Saúde Coletiva, Chapecó, Santa Catarina, Brazil; ${ }^{U}$ Universidade Federal de Pelotas, Programa de Pós-Graduação em Odontologia, Pelotas, Rio Grande do Sul, Brazil; ${ }^{4}$ Universidade Comunitária da Região de Chapecó, Programa de Pós-Graduação em Ciências da Saúde, Chapecó, Santa Catarina, Brazil.

Received: 2019.11.20; Accepted: 2020.06.01.

*Correspondence: rodriguesjunior.sa@unochapeco.edu.br; Tel.: +55-49-3321 8215

\section{HIGHLIGHTS}

- The hydroalcoholic extract of Eugenia uniflora presents antimicrobial potential

- Microbial adherence is affected by the hydroalcoholic extract of Eugenia uniflora

- Surface roughness of the PMMA is not affected by the extract of Eugenia uniflora

- Color change may require different application of the extract of Eugenia uniflora.

Abstract: To the moment, there is no ideal substance for home-based denture disinfection. This study assessed in vitro the antimicrobial effect of the hydroalcoholic extract of Eugenia uniflora and the effect on the physical properties of denture polymethylmethacrylate (PMMA). Candida albicans, Staphylococcus aureus, and Klebsiella oxytoca were isolated from samples of saliva collected from denture wearers. The extracts were produced in three concentrations, according to the Brazilian Pharmacopeia. One hundred eighty-eight disc-shaped specimens of thermopolymerizable PMMA were prepared and randomly allocated to five treatment groups: sterile saline solution ( $0.85 \%$; control); chlorhexidine digluconate $(0.2 \%)$; and hydroalcoholic extract of $E$. uniflora $(0.2 \%, 0.8 \%$, and $1.16 \%)$. The specimens were disinfected for 8 
hours/day for 30 days. Adherence of microorganisms to the surface, PMMA surface roughness, and color stability were assessed. Inferential statistics were performed with one- and two-way ANOVA/Tukey test, and Kruskal Wallis, Mann-Whitney $U$, and paired t-tests, at $\alpha=0.05$. The extract of $E$. uniflora at $0.2 \%$ and $1.16 \%$ reduced the microbial load of $K$. oxytoca, while chlorhexidine digluconate significantly reduced microbial load of all microrganisms. Microbial adherence at day 10 was reduced by all experimental substances $(p<0.001)$. Surface roughness was not affected by the disinfecting substances $(p>0.05)$. Nevertheless, all experimental groups produced unacceptable color change at the end of the disinfection protocol $(p<0.001)$. The nonadherent potential against microorganisms isolated from the oral cavity confirm the potential of use of the hydroalcoholic extract of $E$. uniflora as a denture disinfectant. Yet, unacceptable color changes may occur, regardless of extract concentration.

Keywords: denture disinfectant; E. uniflora; microbial adhesion; microorganisms; Polymethylmethacrylate.

\section{INTRODUCTION}

The ageing process has been characteristically associated with the decline in oral health quality. Tooth loss, for instance, is one of the marked characteristics of the oral health of elderly people, and it is driven by societal and disease-related aspects [1]. This scenario highlights the demand for oral health programs focused on the elderly population and the need for prosthetic rehabilitation [2].

Changes in oral hygiene habits are key to ensure adequate oral health status, even when all natural teeth are replaced with a complete denture. Denture wearers are more vulnerable to oral infections because of quantitative and qualitative alterations in microorganisms, which increase the local inflammatory processes [3]. The microbial load control of denture wearers relies on adequate denture cleansing and it involves routine denture brushing and use of antimicrobial disinfectant solutions [4].

The oral cavity is composed of several species of microorganisms. Most of them, predominantly the aerobic and anaerobic gram-positive cocci, are known to cause oral infections [5,6]. The presence of enterobacteria has been frequently related to oral infections, with dental prosthesis as a facilitating agent for the growth of these microorganisms [7]. Moreover, Candida albicans is the most distinguished among fungi, because it is one of the main opportunistic pathogens present in the oral cavity $[8,9]$. Candida species have been found associated with almost $70 \%$ of complete denture wearers [10], finding in denture polymethylmethacrylate (PMMA) a likely substrate to reside [11].

Alternatives for denture disinfection have included overnight denture immersion in disinfecting substances, such as chlorhexidine digluconate, alkaline peroxide, and sodium hypochlorite $[12,13]$. These substances, regardless of presenting some antimicrobial potential, may lead to PMMA discoloration [13,14]. Therefore, phytomedicines are interesting denture disinfectant alternatives as long as their antimicrobial potential against oral pathogens is proven and they do not produce any physical alterations on structure or surface of denture PMMA [15].

The use of medicinal plants, particularly in an empirical manner, is widespread in Brazil. However, scientific evidence of the therapeutic effects of bioactive extracts has stimulated research in this area to elucidate the mechanisms of action and toxicity of these extracts, and to guarantee their access at low costs [16]. Currently, there is evidence for the therapeutic use of some plant extracts to prevent and treat infections of low severity [16]. The species Eugenia uniflora L. (Myrtaceae) is listed in the National List of Medicinal Plants of Interest to SUS (Brazilian United Health System) (RENISUS), which shows its pharmacological importance. It is native to the Americas, where it is extensively distributed because of its adaptation capacity and is used to treat dyspepsias and inflammations.

Considering the absence of an ideal denture disinfectant solution, this study aimed to: i) characterize the E. unifora extract as a potential phytomedicine for use as a denture disinfectant; ii) to analyze the antimicrobial effect of the hydroalcoholic extract of $E$. uniflora, comparing it to a commercially available oral disinfectant; ii) to analyze the surface roughness and color stability of denture PMMA after exposure to the disinfectant solutions.

\section{MATERIAL AND METHODS}

The population of this exploratory in vitro study comprised 31 wearers of complete dentures made of polymethylmethacrylate (PMMA) who had visited a dental office in the western region of Santa Catarina, Brazil, from November to December 2016. Absence of oral lesions at the time of the study and use of dental 
prostheses for at least one year were required. Subjects undergoing antimicrobial treatment were excluded. The institutional Research Ethics Committee approved this study, under protocol no. 1.752.675/2016.

\section{Microbial preparation}

Saliva was collected with a swab and seeded on plates containing Sabouraud dextrose agar with chloramphenicol (Oxoid), Blood agar (Merck), and MacConkey agar (Merck), using the depletion technique. The plates were incubated at $37^{\circ} \mathrm{C}$ for 24 hours for colony growth. Next, the plates were read, and the species were identified considering color aspects, morphology, and crop texture. Microbial inoculums of $C$. albicans, $S$. aureus, and $K$. oxytoca were prepared from the cultures on specific media, and cell density was adjusted to match scale 1 of the McFarland turbidity standard (approximately $3 \times 10^{8} \mathrm{cells} / \mathrm{mL}$ ).

\section{Plant material}

The leaves of E. uniflora were collected in Chapecó, Santa Catarina, Brazil $\left(27^{\circ} 05^{\prime} 41.43^{\prime \prime} S\right.$ and $\left.52^{\circ} 39^{\prime} 39.19 " \mathrm{~W}\right)$ in October 2016. The plant material was identified by Osmar dos Santos Ribas, curator of the Municipal Botanical Museum Herbarium of Curitiba, PR, Brazil, and deposited under registration number MBM 316818.

\section{Preparation of extracts of Eugenia uniflora and chemical analysis}

A sample of the dried aerial parts of E. uniflora $(500 \mathrm{~g})$ of same particle size was collected by passage through a mesh $(425 \mu \mathrm{m} ; 35$ Tyler/Mesch). The sample was extracted in a percolator tube with $70 \% \mathrm{EtOH}$ (v/v) according to the Brazilian Pharmacopoeia 5 [17]. The hydroalcoholic extract of E. uniflora (HEEu) was concentrated to dryness under reduced pressure at $40^{\circ} \mathrm{C}$ and, then, freeze-dried and stored at $-20^{\circ} \mathrm{C}$. For the chemical characterization of E. uniflora, the chromatographic analysis was performed using a Varian ProStar HPLC system consisting of an automatic injector, ternary gradient detectors, pumps, and a UV/Vis Kromasil C18 reversed-phase ODS column $\left(5 \mu \mathrm{m} ; 25 \times 4.5 \mathrm{~mm}^{2}\right)$. The mobile phase consisted of two solvents: $\mathrm{MeOH}$ (solvent $\mathrm{A}): \mathrm{H}_{2} \mathrm{O}\left(\mathrm{HCO}_{2} \mathrm{H} 0.3 \% \mathrm{v} / \mathrm{v}\right)$ (solvent B). The gradient used was $20 \% \mathrm{~A}$ for 6 minutes, $52 \% \mathrm{~A}$ for 15 minutes, $72 \% A$ for 27 minutes and $10 \% A$ for 30 minutes. The flow rate was $0.8 \mathrm{ml} / \mathrm{minute}$ and the injection volume was $20 \mu \mathrm{L}$. UV absorbance at $370 \mathrm{~nm}$ was measured, and the results were then compared with the retention times of an authentic external standard followed by a UV spectrum analysis. Six different concentrations of quercetin (3.12, 6.25, 12.5, 25 and $50 \mathrm{\mu g} / \mathrm{ml}$; Sigma-Aldrich) were analyzed in triplicates and a calibration curve was generated. HEEu was partitioned into a separatory funnel with ethyl acetate (AcOEt) and the fraction AcOEt was dissolved in $\mathrm{MeOH}(1 \mathrm{mg} / \mathrm{ml})$, and subjected to solid phase extraction (Phenomenex Stracta C18-E:FAFSE) before the chromatographic profile was generated. The results are expressed as the concentration of quercetin per gram of HEEu and in the dried plant material.

\section{Preparation of PMMA specimens}

Simultaneously, 150 disc-shaped specimens of PMMA (10 mm of diameter $\times 2 \mathrm{~mm}$ of thickness) were made in wax and molded in gypsum plaster. Following, the discs were remade using thermopolymerizable PMMA resin (medium pink with veins; Clássico). Finishing was performed manually and was followed by polishing using horsehair discs soaked in pumice stone (Asfer), and felt (Vipibril). Then, all specimens were exposed to ultraviolet light for thirty minutes on each side for disinfection.

A sample size of four test specimens per group was calculated using $G^{*}$ Power 3.1.9.2 (Universität Düsseldorf, Germany), considering a Type I error of $0.05,95 \%$ test power (one-tailed), and effect size of 3.3 based on a clinically visible $\Delta \mathrm{E}^{*}[18]$.

\section{Disinfection protocol}

The protocol was initiated by immersing the test specimens in $4 \mathrm{~mL}$ of liquid culture medium containing the microbial inoculum and incubating them at $37^{\circ} \mathrm{C}$ for 16 hours/day [15]. Then, the specimens were randomly divided into five groups and immersed for disinfecting purposes in $0.85 \%$ sterile saline solution (negative control), in a dental disinfectant containing $0.2 \%$ chlorhexidine gluconate (positive control) (Riohex), or in the hydroalcoholic extract of E. uniflora at concentrations of $0.2 \%, 0.8 \%$, and $1.16 \%$. Immersion lasted 
for 8 hours/day simulating night time with a total of 30 days of testing [19]. Following, the specimens were returned to sterilized test tubes containing culture medium.

\section{Antimicrobial analysis}

The reduction of microbial load $(n=45)$ was analyzed by seeding and counting the CFUs on Sabouraud dextrose agar plates followed by PCA, at 1 and 30 days of the protocol. The culture medium was renewed during the experiment to avoid microbial reduction due to lack of nutrients.

The ability of microorganisms to adhere to the PMMA surface $(n=45)$ was evaluated at day 10 of the experiment. The specimens were sonicated in an ultrasonic cell disruptor (USC 800A) at a frequency of 40 $\mathrm{kHz}$, for 15 minutes at room temperature. Next, the samples were seeded in Plate Count Agar (PCA) (Merck) or Sabouraud dextrose agar with chloramphenicol (Oxoid), and incubated for 24 hours at $37^{\circ} \mathrm{C}$ to count the colony-forming units (CFU) [20].

\section{Analysis of effects on PMMA}

The color and surface roughness of the PMMA discs $(n=60)$ were evaluated before and after the disinfection protocol (1 and 30 days). Color was analyzed with an Easyshade visible ultraviolet reflection spectrophotometer (Vita Zahnfabrik). Color changes were calculated according to the CIEL*a*b* system. $L^{*}$, $a^{*}$ and $b^{*}$ values before and after the disinfection protocol allowed the determination of a $\Delta$ for each parameter and, ultimately, the calculation of the $\Delta \mathrm{E}^{*} . \Delta \mathrm{E}^{*}$ is a nondirectional summary of color change based on the $\Delta s$ of each directional parameter, as follows:

$$
\Delta E_{a b}^{*}=\sqrt{\left(L_{2}^{*}-L_{1}^{*}\right)^{2}+\left(a_{2}^{*}-a_{1}^{*}\right)^{2}+\left(b_{2}^{*}-b_{1}^{*}\right)^{2}}
$$

The $\Delta \mathrm{E}^{*}$ measurements were classified into three clinically relevant intervals, as follows: $\Delta \mathrm{E}^{*}<1$ (undetectable color change), $1<\Delta \mathrm{E}^{*}<3.3$ (clinically acceptable color change), and $\Delta \mathrm{E}^{*}>3.3$ (clinically unacceptable color change) [21].

Surface roughness was measured with a RP-200 roughness meter (Instrutherm) by three parallel readings along a 4-mm length with a cut-off configuration of $0.8 \mathrm{~mm}$ to quantify the changes in surface roughness $(\mathrm{Ra}-\mu \mathrm{m})$.

\section{Statistical analysis}

The adherence of data to normal distribution was verified using the Anderson-Darling test. The microbial loads before and after the disinfection protocol were compared with two-way ANOVA and Tukey test. Oneway ANOVA and Tukey test were used to compare microbial adherence at day 10. Color changes between days 1 and 30 were expressed as mean $\Delta \mathrm{E}$ and compared using Kruskal Wallis and Mann-Whitney $\mathrm{U}$ test. Changes in roughness between days 1 and 30 were analyzed using the paired t-test. The tests were performed using the Minitab 17.0 statistical package at 5\% significance level.

\section{RESULTS}

The extraction by means of percolation, as well as the process of partitioning and obtaining the ethyl acetate fraction proved to be efficient for the detection of $E$. uniflora chemical compounds. Thus, HPLC analyzes revealed a high concentration of flavonoid quercetin in the hydroalcoholic extract of the plant (Figure 1 and Table 1).

Table 1. Quercetin concentration obtained by high performance liquid chromatography (HPLC) ethyl acetate fraction, in the hydroalcoholic extract and in the dry plant of Eugenia uniflora L. (Myrtaceae)*

$\begin{array}{ccccc}\text { Samples } & \text { Concentration } & \text { Quercetin }(\mathrm{mg}) \text { in the } & \text { Quercetin }(\mathrm{mg}) \text { in the } & \text { Quercetin }(\mathrm{mg}) \text { in the } \\ (10 \mathrm{mg} / \mathrm{mL}) & (\mu \mathrm{g} / \mathrm{mL}) & \text { acetate fraction } & \text { fluid extract } & \text { dry plant }(100 \mathrm{~g})\end{array}$

\section{FAFSE}

25.41

8.28

34.08

17.04

* Roman Júnior ${ }^{22}$ 

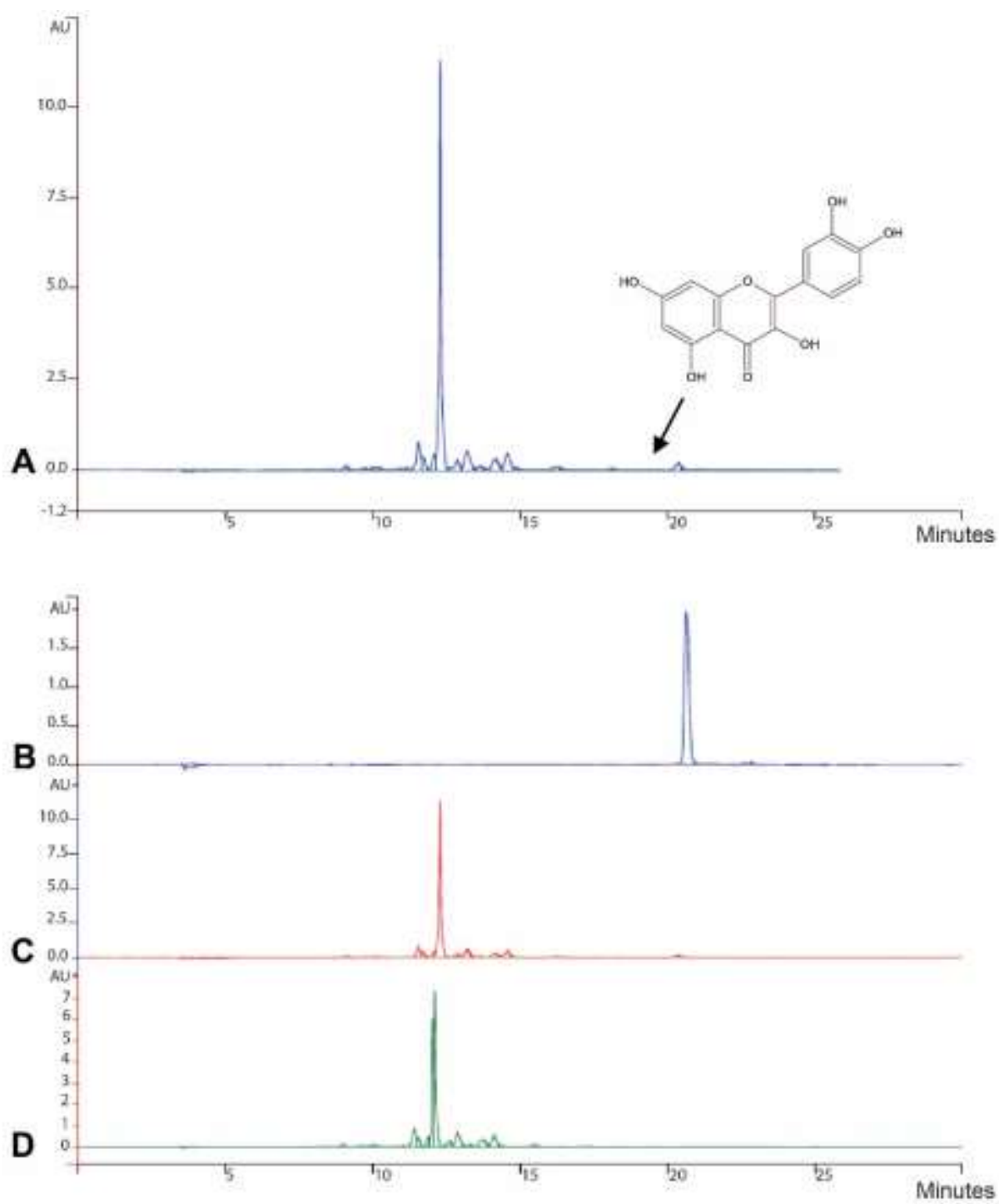

Figure 1. High-performance liquid chromatography of the ethyl acetate fraction of Eugenia uniflora L. (Myrtaceae) leaves $(10 \mathrm{mg} / \mathrm{mL}$ in $\mathrm{MeOH}):(a)$ Highlight to the presence of quercetin in the ethyl acetate fraction submitted to solid phase extraction; (b) Quercetin standard (12.5 $\mu \mathrm{g} / \mathrm{mL}$ in $\mathrm{MeOH}$ ) (Rf: $20.6 \mathrm{~min}$ ); C. Ethyl acetate fraction submitted to solid phase extraction; $D$. Ethyl acetate fraction. Varian ${ }^{\circledR}$ Chromatograph, Kromasil囚 ODS column $(5 \mu \mathrm{m}) \mathrm{C}-18$ reverse phase $\left(25 \times 4.5 \mathrm{~mm}\right.$ ) at a temperature of $24^{\circ} \mathrm{C} \pm 2{ }^{\circ} \mathrm{C}$. Solvents used: $\mathrm{MeOH}$ : (solvent $\left.\mathrm{A}\right): \mathrm{H}_{2} \mathrm{O}\left(\mathrm{HCO}_{2} \mathrm{H} 0.3 \% \mathrm{v} / \mathrm{v}\right)$ (solvent $\left.\mathrm{B}\right)$. The gradient used was $20 \%$ of $A$ for $6 \mathrm{~min}, 52 \%$ of $A$ for $15 \mathrm{~min}, 72 \%$ of $A$ for $27 \mathrm{~min}$ and $10 \%$ of $A$ for $30 \mathrm{~min}$. The flow rate was of $0.8 \mathrm{~mL} / \mathrm{min}$ and detections was at $370 \mathrm{~nm}$. Source: Roman Junior [22].

The colony-forming unit $(\mathrm{CFU} / \mathrm{mL})$ counts of all three microorganism species were affected by the type of disinfecting substance $(p<0.001)$, by disinfecting time $(p<0.001)$ and by the interaction between both $(p<0.001)$. In general, a numerical reduction of CFU counts was observed after disinfection with all substances, except the saline solution. Still, only chlorhexidine produced statistically significant CFU reduction for Staphylococcus aureus and Candida albicans. Klebsiella oxytoca had significant reduction of CFU counts with E. uniflora at $0.2 \%, 1.16 \%$ and chlorhexidine (Table 2). 
Table 2. Reduction of microbial load of Staphylococcus aureus, Candida albicans and Klebsiella oxytoca (x107UFC/mL) in the experimental groups after the disinfection protocol $(n=3)$

\begin{tabular}{llcc}
\hline Microrganism & Disinfectant & Day 1 & Day 30 \\
& & Mean \pm SD & Mean \pm SD \\
\hline & Saline solution & $37.00 \pm 2.65^{\mathrm{ab}}$ & $36.33 \pm 4.16^{\mathrm{ab}}$ \\
& E. uniflora at $0.2 \%$ & $39.00 \pm 4.00^{\mathrm{a}}$ & $32.00 \pm 5.29^{\mathrm{ab}}$ \\
Staphylococcus aureus & E. uniflora at 0.8\% & $35.67 \pm 2.52^{\mathrm{ab}}$ & $29.00 \pm 3.61^{\mathrm{b}}$ \\
& E. uniflora at 1.16\% & $36.00 \pm 2.65^{\mathrm{ab}}$ & $28.67 \pm 4.73^{\mathrm{b}}$ \\
& Chlorhexidine 0.2\% & $36.33 \pm 1.53^{\mathrm{ab}}$ & $6.63 \pm 0.42^{\mathrm{c}}$ \\
& & & \\
Candida albicans & Saline solution & $38.67 \pm 4.04^{\mathrm{a}}$ & $39.00 \pm 3.00^{\mathrm{a}}$ \\
& E. uniflora at 0.2\% & $41.67 \pm 2.08^{\mathrm{a}}$ & $36.67 \pm 2.08^{\mathrm{a}}$ \\
& E. uniflora at 0.8\% & $41.33 \pm 3.21^{\mathrm{a}}$ & $36.33 \pm 4.04^{\mathrm{a}}$ \\
& E. uniflora at 1.16\% & $40.33 \pm 1.53^{\mathrm{a}}$ & $37.00 \pm 3.61^{\mathrm{a}}$ \\
& Chlorhexidine 0.2\% & $40.67 \pm 2.08^{\mathrm{a}}$ & $7.90 \pm 0.30^{\mathrm{b}}$ \\
& & & \\
& Saline solution & $34.33 \pm 3.06^{\mathrm{abc}}$ & $34.33 \pm 4.04^{\mathrm{abc}}$ \\
& E. uniflora at 0.2\% & $36.67 \pm 1.53^{\mathrm{a}}$ & $28.67 \pm 2.31^{\mathrm{bc}}$ \\
& E. uniflora at 0.8\% & $35.33 \pm 3.06^{\mathrm{ab}}$ & $29.33 \pm 3.51^{\mathrm{abc}}$ \\
& E. uniflora at 1.16\% & $35.33 \pm 2.08^{\mathrm{ab}}$ & $26.67 \pm 1.53^{\mathrm{c}}$ \\
& Chlorhexidine 0.2\% & $36.00 \pm 3.61^{\mathrm{ab}}$ & $7.43 \pm 0.40^{\mathrm{d}}$ \\
\hline
\end{tabular}

Different superscript letters indicate statistically significant differences within comparisons of substances and times for each microrganism $(p<0.05)$

The ANOVA results showed that all experimental groups were significantly more effective in reducing the microbial adherence of all microorganisms tested when compared to the control group $(p<0.001)$. A significantly lower adherence of $C$. albicans was perceived at concentrations of $0.8 \%$ and $1.16 \%$ under the anti-adherent effect of $E$. uniflora extract $(0.2 \%)$ when compared to that of chlorhexidine (Table 3$)$.

Table 3. Adherence of microrganisms $\left(\times 10^{6} \mathrm{UFC} / \mathrm{mL}\right)$ in the PMMA surface $(n=9)$

\begin{tabular}{lccc}
\hline \multicolumn{1}{c}{ Disinfectant } & S. aureus & C. albicans & K. oxytoca \\
& Mean \pm SD & Mean \pm SD & Mean \pm SD \\
\hline Saline solution & $47.330^{\mathrm{b}}$ & $36.667^{\mathrm{c}}$ & $43.000^{\mathrm{b}}$ \\
E. uniflora at $0.2 \%$ & $3.667^{\mathrm{a}}$ & $3.600^{\mathrm{ab}}$ & $4.233^{\mathrm{a}}$ \\
E. uniflora at $0.8 \%$ & $3.133^{\mathrm{a}}$ & $2.467^{\mathrm{a}}$ & $3.267^{\mathrm{a}}$ \\
E. uniflora at $1.16 \%$ & $3.533^{\mathrm{a}}$ & $2.033^{\mathrm{a}}$ & $1.633^{\mathrm{a}}$ \\
Chlorhexidine $0.2 \%$ & $1.767^{\mathrm{a}}$ & $4.267^{\mathrm{b}}$ & $3.067^{\mathrm{a}}$ \\
\hline
\end{tabular}

Different superscript letters in each column represent statistically significant differences between disinfecting substances (Tukey's test, $p<0.05$ ).

Color stability was significantly higher in the negative control group $(p<0.001)$. All other experimental groups exceeded the $\Delta \mathrm{E}$ threshold, suggesting a clinically unacceptable color change (Table 4). There were no statistically significant differences in surface roughness between groups before or after the disinfection 
protocol $(p>0.05)$, proving that this characteristic remained almost unchanged at the end of the test period (Table 5).

Table 4. Mean color change $(\Delta \mathrm{E})$ produced by the denture disinfectants at the end of the disinfection protocol

\begin{tabular}{lcccc}
\hline Disinfectant & Mean $\Delta \mathrm{E} \pm \mathrm{SD}$ & Median & Minimum & Maximum \\
\hline Saline solution & $2.78 \pm 2.28^{\mathrm{a}}$ & 1.74 & 0.29 & 9.03 \\
E. uniflora at $0.2 \%$ & $10.01 \pm 5.68^{\mathrm{b}}$ & 9.05 & 1.31 & 21.40 \\
E. uniflora at $0.8 \%$ & $9.12 \pm 6.71^{\mathrm{b}}$ & 6.63 & 1.43 & 24.43 \\
E. uniflora at $1.16 \%$ & $9.09 \pm 5.86^{\mathrm{b}}$ & 8.03 & 0.47 & 20.16 \\
Chlorhexidine $0.2 \%$ & $7.92 \pm 5.48^{\mathrm{b}}$ & 7.35 & 0.69 & 19.84 \\
\hline
\end{tabular}

Different letters indicate statistically significant differences between groups (Kruskal Wallis and Mann Whitney, $\mathrm{p}<0.001)$.

Table 5. Mean surface roughness $(\mathrm{Ra}-\mu \mathrm{m})$ produced by the denture disinfectants at the end of the disinfection protocol

\begin{tabular}{lcccc}
\hline Disinfectant & $\begin{array}{c}\text { Day } 1 \\
\text { Mean Ra } \pm \text { SD }\end{array}$ & $\begin{array}{c}\text { Day 30 } \\
\text { Mean Ra } \pm \text { SD }\end{array}$ & $\Delta$ & $p$ \\
\hline Saline solution & $0.1976 \pm 0.0412$ & $0.2047 \pm 0.0463$ & -0.0070 & 0.497 \\
E. uniflora at 0.2\% & $0.1844 \pm 0.0477$ & $0.1989 \pm 0.0518$ & -0.0145 & 0.220 \\
E. uniflora at 0.8\% & $0.1898 \pm 0.0584$ & $0.1869 \pm 0.0421$ & 0.0029 & 0.810 \\
E. uniflora at 1.16\% & $0.2108 \pm 0.0536$ & $0.1968 \pm 0.0449$ & 0.0140 & 0.233 \\
Chlorhexidine 0.2\% & $0.1954 \pm 0.0408$ & $0.1953 \pm 0.0453$ & 0.0001 & 0.989 \\
\hline
\end{tabular}

\section{DISCUSSION}

Denture disinfection performed by the professional or by the patient under professional supervision, helps eliminating microbiological pathogens and it should be included in the oral hygiene routine. Several chemical substances with antimicrobial potential have been available for patients to disinfect dentures and control biofilm [14,23]. However, the long-term deleterious effects of these substances on denture polymethylmethacrylate (PMMA), such as discoloration and reduction of flexural strength [14], have led to the search for disinfecting alternatives, including phytomedicines.

The results of this study revealed that the hydroalcoholic extracts of $E$. uniflora were effective in reducing the microbial load of clinical isolates when applied at $0.2 \%$ and $1.16 \%$ for $K$. oxytoca only. Chlorhexidine, on the other hand, produced a far higher reduction for all three microrganisms (Table 2). Even so, a numerical reduction in CFU count was observed for all microrganisms with the extracts. Also, the reduction of $C$. albicans adherence (Table 3 ) was significantly higher using the $0.8 \%$ and $1.16 \%$ extracts of $E$. uniflora when compared with the positive control (chlorhexidine). The importance of these findings resides on the fact that Candida species and, most predominantly, C. albicans, have been implied in the occurrence and severity of denture stomatitis symptoms [4]. According to Gendreau and Loewy [4], the susceptibility of Candida colonization is highly associated with lack of denture hygiene, reinforcing the need for routine cleansing and decontamination. This scenario reinforces chlorhexidine as the main disinfecting solution and $E$. uniflora solution as a potential alternative, although with lower antimicrobial properties.

All microrganisms studied are potentially pathogenic and frequently seen in the elderly population. Our findings corroborate other results regarding the microbial reduction of $S$. aureus [24], C. albicans [25] and $K$. oxytoca [26], and they should be considered a starting point for further studies on the use of this natural substance for disinfecting dentures. The presence of anthraquinone heterosides, steroids, triterpenes, tannins, flavonoids, and saponin heterosides may justify some of the biological activities, including the antimicrobial activity of this plant. This in vitro antimicrobial effect of $E$. uniflora could be considered sufficient to indicate clinical tests using this substance as a disinfectant solution for denture PMMA. In addition, considering that poorly sanitized surfaces may trigger biofilm formation and infections [15], the anti-adherent 
effect shown by this extract complements its potential of use, because it affects microbial adhesion and biofilm formation on the PMMA surface.

Similar results of microbial reduction of the three microorganisms were observed with the various concentrations of $E$. uniflora extract, with no statistically significant differences among groups. In comparison, a significant reduction in microbial load was perceived with chlorhexidine when compared with the extracts (Table 2). Still, the long-term exposure to chlorhexidine has been associated to drawbacks, such as denture discoloration, darkening of natural teeth, burning sensation, and changes in taste [27]. Therefore, the potentials of natural substances, such as neither affecting the denture structure nor causing harm to the individual, and being inexpensive and easy to use [15], should be considered. The similar antimicrobial effect of $E$. uniflora extract on the different microorganisms tested maintains the expectations regarding its antimicrobial action in the oral cavity [5].

The anti-adherent activity of all disinfectant solutions was high for all microorganisms and it is important when considering the $E$. uniflora extract a potential substance for denture disinfection. As aforementioned, the ability to reduce microbial adherence on PMMA surface inhibits biofilm formation and it is highly expected from a disinfectant solution.

No substance altered significantly the surface roughness of the PMMA discs (Table 5). It is well recognized that denture PMMA undergoes degradation in humid environment over time, which may cause porosity of the denture surface [28]. Moreover, the denture material may be exposed to a variety of chemicals, including denture disinfectants, whose chemistry may affect the polymer network [28]. Nonetheless, changes in the surface roughness of acrylic resins by the application of chlorhexidine digluconate are rare [29]. The results of this study also revealed that surface roughness was not affected by the contact with the $E$. uniflora extracts. The maintenance of roughness characteristics of the PMMA surface is a positive factor, considering a rough surface facilitates microbial adhesion to the material, causing the formation of biofilms and consequently the development of oral disease.

In contrast, all the substances tested, with exception of the negative control, affected significantly the PMMA color stability, resulting in a clinically unacceptable color change $\left(\Delta E^{*}>3.3\right)($ Table 4$)$. Intrinsic and extrinsic pigments are often used to combine the denture with the human tissue, and the intrinsic staining is less vulnerable to environmental conditions and prosthesis handling [30]. Thus, accumulation of extrinsic pigments on the PMMA surface may have resulted from the contact with the E. uniflora extract. Notably, this pigmentation, even at the lowest extract concentration, was similar to the one caused by the standard disinfectant solution (chlorhexidine).

E. uniflora has received attention as a potential phytomedicine by its adaptation capacity to different weather and soil conditions and its antimicrobial and anti-inflammatory activities. The addition of $E$. uniflora hydroalcoholic extract to an experimental dentifrice reduced gingivitis and confirmed the antimicrobial effect against oral pathogens [31]. In the experimental design proposed, the lowest concentration of $E$. uniflora was set to compare its effects with the concentration of the positive control. The two other concentrations were included, helping to establish a possible concentration-dependent activity, which was not observed (Tables 2 and 3 ).

The antimicrobial effect against $K$. oxytoca and the anti-adherent effect of $E$. uniflora hydroalcoholic extract reinforces its potential use as denture disinfectant. However, the discoloration resulting from soaking the PMMA in the extract for 8 hours suggests that alternatives to this protocol should be considered. Reducing the concentration of the extract or considering different application protocols with varying immersion times or by spraying the substance on the denture surface may generate alternatives that do not discolor the denture.

The use of strains isolated from the oral cavity of individuals in this study reflected the clinical scenario and the virulence potential of the microorganisms [32], and the 30-day night application represents a viable and straightforward disinfection protocol in the daily maintenance of oral hygiene.

\section{CONCLUSION}

This in vitro study characterized the extract of $E$. uniflora and confirmed the anti-adherent effect of the hydroalcoholic extract of $E$. uniflora against microorganisms isolated from the oral cavity of dental PMMA wearers. Chlorhexidine, though, presented a higher antimicrobial effect. Also, in light of the discoloration potential of $E$. uniflora, if one considers using it for denture disinfection, further studies testing varying application protocols other than immersion for eight hours are required. In addition, clinical trials are indispensable to explore the effectiveness of these results and to subsidize a new alternative for effective oral hygiene. 
Funding: This research received no external funding.

Conflicts of Interest: The authors declare no conflict of interest.

\section{REFERENCES}

1. Murray Thomson W. Epidemiology of oral health conditions in older people. Gerodontology. 2014 Feb;31(Suppl 1):9-16.

2. Ribeiro CG, Cascaes AM, Silva AE, Seerig LM, Nascimento GG, Demarco FF. Edentulism, severe tooth loss and lack of functional dentition in elders: A study in Southern Brazil. Braz Dent J. 2016 May-Jun;27(3):345-52.

3. Andrade MC, Ribeiro AP, Dovigo LN, et al. Effect of different pre-irradiation times on curcumin-mediated photodynamic therapy against planktonic cultures and biofilms of Candida spp. Arch Oral Biol. 2013 Feb;58(2):20010.

4. Gendreau L, Loewy ZG. Epidemiology and etiology of denture stomatitis. J Prosthodont. 2011 Jun;20(4):251-60.

5. Zilberstein B, Quintanilha AG, Santos M, et al. Digestive tract microbiota in healthy volunteers. Clinics. 2007 Feb;62(1):47-54.

6. Ogle OE. Odontogenic infections. Dent Clin North Am. 2017 Apr;61(2):235-52.

7. Gaetti-Jardim E, Nakano V, Wahasugui TC, Cabral FC, Gamba R, Avila-Campos MJ. Occurrence of yeasts, enterococci and other enteric bacteria in subgingival biofilm of HIV-positive patients with chronic gingivitis and necrotizing periodontitis. Braz J Microbiol. 2008 Apr;39(2):257-61.

8. Valentini F, Luz MS, Boscato N, Pereira-Cenci T. Biofilm formation on denture liners in a randomised controlled in situ trial. J Dent. 2013 May;41(5):420-7.

9. Hirota K, Yumoto H, Sapaar B, Matsuo T, Ichikawa T, Miyake Y. Pathogenic factors in Candida biofilm-related infectious diseases. J Appl Microbiol. 2017 Feb;122(2):321-30.

10. Loster BW, Loster J, Wieczorek A, Ryniewicz W. Mycological analysis of the oral cavity of patients using acrylic removable dentures. Gastroenterol Res Pract. 2012:951572. doi:10.1155/2012/951572.

11. O'Donnell LE, Alalwan HKA, Kean R, et al. Candida albicans biofilm heterogeneity does not influence denture stomatitis but strongly influences denture cleansing capacity. J Med Microbiol. 2017 Jan;66(1):54-60.

12. Muscat $\mathrm{Y}$, Farrugia C, Camilleri L, Arias-Moliz MT, Valdramidis V, Camilleri J. Investigation of acrylic resin disinfection using chemicals and ultrasound. J Prosthodont. 2018 Jun;27(5):461-8.

13. Panariello BH, Izumida FE, Moffa EB, Pavarina AC, Jorge JH, Giampaolo ET. Effect of mechanical toothbrushing combined with different denture cleansers in reducing the viability of a multispecies biofilm on acrylic resins. Am $\mathrm{J}$ Dent. 2016 Jun;29(3):154-60.

14. Peracini A, Machado Andrade I, Oliveira VC, et al. Antimicrobial action and long-term effect of overnight denture cleansers. Am J Dent. 2017 Apr;30(2):101-8.

15. Guiotti AM, Cunha BG, Paulini MB, et al. Antimicrobial activity of conventional and plant-extract disinfectant solutions on microbial biofilms on a maxillofacial polymer surface. J Prosthet Dent. 2016 Jul;116(1):136-43.

16. Calixto JB. Efficacy, safety, quality control, marketing and regulatory guidelines for herbal medicines (phytotherapeutic agents). Braz J Med Biol Res. 2000 Feb;33(2):179-89.

17. Farmacopéia ANDVS. Farmacopeia Brasileira. 5a edição. Brasília: Anvisa, 2010. 546 p.

18. Abu-Bakr N, Han L, Okamoto A, Iwaku M. Color stability of compomer after immersion in various media. J Esthet Restor Dent. 2000;12(5):258-63.

19. Khan MA, Dhaded S, Shalini BN. Commercial and plant extract denture cleansers in prevention of candida albicans growth on soft denture reliner: In vitro study. J Clin Diagnostic Res 2016 Feb;10(2):ZC42-ZC45. doi: 10.7860/JCDR/2016/12558.7228.

20. Tondo EC, Machado TRM, Malheiros P da S, Padrão DK, de Carvalho AL, Brandelli A. Adhesion and biocides inactivation of Salmonella on stainless steel and polyethylene. Braz J Microbiol. 2010 Oct;41(4):1027-37.

21. Guiotti AM, Goiato MC, Dos Santos DM, et al. Comparison of conventional and plant-extract disinfectant solutions on the hardness and color stability of a maxillofacial elastomer after artificial aging. J Prosthet Dent. 2016 Apr;115(4):501-8.

22. Roman Junior WA. Estudo farmacognóstico para as espécies medicinais Alpinia zerumbet, Solidago chilensis e Eugenia uniflora [tese de doutorado]. Curitiba: Universidade Federal do Paraná, Setor de Ciências da Saúde; 2013. $188 \mathrm{p}$.

23. Valentini-Mioso F, Maske TT, Cenci MS, Boscato N, Pereira-Cenci T. Chemical hygiene protocols for complete dentures: A crossover randomized clinical trial. J Prosthet Dent 2019 Jan;121(1):83-9. 
24. Bernardo THL, Sales Santos Veríssimo RC, Alvino V, et al. Antimicrobial Analysis of an Antiseptic Made from Ethanol Crude Extracts of P. granatum and E. uniflora in Wistar Rats against Staphylococcus aureus and Staphylococcus epidermidis. Sci World J. 2015;2015:751791. doi: doi.org/10.1155/2015/751791.

25. Silva-Rocha WP, de Brito Lemos VL, Ferreira MRA, et al. Effect of the crude extract of Eugenia uniflora in morphogenesis and secretion of hydrolytic enzymes in Candida albicans from the oral cavity of kidney transplant recipients. BMC Complement Altern Med. 2015 Feb;15(5):6. doi: 10.1186/s12906-015-0522-x.

26. Adeola Segun A, Alli-balogun G, Adeyinka O, Kasali A, Eshilokun O. Partial Purification and Characterization of Extracellular Proteases of Klebsiella oxytoca and Its Inhibition by the Volatile Oil of Eugenia uniflora. Am J Biochem. 2013;3(2):34-9.

27. Scheibler E, Garcia MCR, Medina da Silva R, Figueiredo MA, Salum FG, Cherubini K. Use of nystatin and chlorhexidine in oral medicine: Properties, indications and pitfalls with focus on geriatric patients. Gerodontology. 2017 Sep;34(3):291-8.

28. Ferracane JL. Hygroscopic and hydrolytic effects in dental polymer networks. Dent Mater. 2006 Mar;22(3):211-22.

29. Schwindling FS, Rammelsberg P, Stober T. Effect of chemical disinfection on the surface roughness of hard denture base materials: a systematic literature review. Int J Prosthodont. 2014 May-Jun;27(3):215-25.

30. Hu X, Pan X, Johnston WM. Effects of pigments on dynamic mechanical properties of a maxillofacial prosthetic elastomer. J Prosthet Dent. 2014 Nov;112(5):1298-303.

31. Jovito V de C, Freires IA, Ferreira DA, Paulo Mde Q, Castro RD. Eugenia uniflora dentifrice for treating gingivitis in children: Antibacterial assay and randomized clinical trial. Braz Dent J. 2016 Jul-Aug;27(4):387-92.

32. Ferrari DO, Lund RG, Zanella L, Roman Júnior WA, Rodrigues-Junior SA. Denture disinfection using Salvia officinalis L: microbial load and selected properties of PMMA. Braz J Oral Sci. 2019 Jan; p. e18901. doi: 10.20396/bjos.v17i0.8654158.

2020 by the authors. Submitted for possible open access publication under the terms and conditions of the Creative Commons Attribution (CC BY NC) license (https://creativecommons.org/licenses/by-nc/4.0/). 